Revista Brasileira de Farmacognosia Brazilian Journal of Pharmacognosy 21(4): 730-736, Jul./Aug. 2011

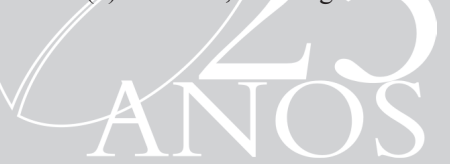

Article

Received 1 Nov 2010

Accepted 14 Feb 2011

Available online 17 Jun 2011

Keywords:

acute toxicity

catalase

medial lethal dose

Passiflora nepalensis

sub-acute toxicity

ISSN 0102-695X

doi: $10.1590 / \mathrm{S} 0102-695 \mathrm{X} 2011005000103$

\section{Acute and sub-acute toxicity studies of Passiflora nepalensis in rats}

\author{
Sita Sharan Patel, ${ }^{* 1}$ Shashi Verma, ${ }^{1}$ Govind Nayak, ${ }^{2}$ Akhlesh \\ Kumar Singhai, ${ }^{2}$ N Ganesh ${ }^{3}$
}

${ }^{I}$ Department of Pharmacology, Himalayan Pharmacy Institute, India, ${ }^{2}$ Department of Pharmacology, Lakshmi Narain College of Pharmacy, India, ${ }^{3}$ Department of Research, Jawaharlal Nehru Cancer Hospital \& Research Centre, India.

\begin{abstract}
This study was designed to elucidate the toxicity of widely used plant Passiflora nepalensis Walp. (Passifloraceae) in rats. We have taken methanolic extract isolated from whole plant of Passiflora nepalensis and studied their toxic effects. Acute, sub-acute toxicities and LD50 values were determined in experimental rats. The external appearance of the dead animals, the appearance of the viscera, heart, lungs, stomach, intestine, liver, kidney, spleen and brain were carefully noted and any apparent and significant features or differences from the normal were recorded after acute treatment with methanolic extract of whole plant of Passiflora nepalensis (MPN). Following the sub-acute administration of MPN for fourteen days, the vital organ such as liver, kidney and heart were carefully evaluated by histopathological and biochemical studies and any apparent and significant changes or differences from the normal were recorded. Pathologically, neither gross abnormalities nor histopathological changes were observed. Oral administration of MPN at the doses of 40, 80, 160 and $320 \mathrm{mg} / \mathrm{kg}$ body wt for fourteen consecutive days to male and female rats did not induce any short term toxicity. Collectively, these data demonstrate that the methanolic extract of Passiflora nepalensis have a high margin of safety.
\end{abstract}

\section{Introduction}

The genus Passiflora consists of 500 species which are mostly found in warm and tropical regions. Passiflora comes from Latin word "Passio" that was first time discovered by Spanish discoverers in 1529 and was described as a symbol for "Passion of Christ" (Kinghorn, 2001; Dhawan et al., 2004). This plant was used widely in traditional medicine in West India, Mexico, Netherland, South America, Italia and Argentina. One of species of this genus named as Passiflora nepalensis Walp. (Passifloraceae) is more popular than its other species in Eastern India. Passiflora nepalensis is used in folklore medicine for treating hypertension and inflammation (Patel, 2009; Patel et al., 2009). Passiflora nepalensis (Passion flower Family) is a wide spreading climber, grown frequently in gardens as an ornamental. Stems wiry, leaves three lobed and serrate, flower pale pink in color and fruits ovoid or globose. This is a fine climber suitable for covering arbours, verandahs and arches. It can be propagated by seed or layering. The fruit is edible when ripe (The Wealth of India, 2001). Its medicinal usage has been reported in the traditional systems of medicine such as Ayurveda, Siddha and Unani. Passiflora contains several compounds including alkaloids, phenols, glycosyl flavonoids and cyanogenic compounds (Dhawan et al., 2004; Patel, 2009; Patel et al., 2009). Antihypertensive and negative chronotropic effects of Passiflora nepalensis have been investigated earlier. Furthermore, it has been traditionally claimed by rural community of Sikkim State for its lipid lowering property and therapeutic importance in cardiovascular disorders. Its folkloric use and antihypertensive effect due to protection against renal ischemia/reperfusion have also been established (Patel et al., 2010).

Toxicity is defined as any harmful effect of chemical or a drug on a target organism. Acute and subacute toxicities have been defined by various experts. The Organization for Economic Co-operation and Development panel of experts (OECD Guidelines, 1980) defines acute toxicity as "the adverse effects occurring within a short time of administration of a single dose of a substance or multiple dose given within 24 hours and sub-acute toxicity as "the adverse effects occurring as a result of the repeated daily dosing of chemical to experimental animals for fourteen days" (Veerappan et al., 2007). The plant Passiflora nepalensis traditionally 
used for the treatment of inflammation, malaria and hypertension in Sikkim and other Himalayan regions but there is not any scientific data available regarding their toxicity. Hence the present work designed to evaluate the acute and sub-acute toxicity studies of Passiflora nepalensis, is an attempt to provide a direction for further research.

\section{Materials and Methods}

\section{Animals}

Wister albino rats, both male and female, weighing 200 to $250 \mathrm{~g}$, were used for the experiment. They were housed in standard environmental conditions like, ambient temperature $\left(25 \pm 1^{\circ} \mathrm{C}\right)$, relative humidity $(55 \pm 5 \%)$ and $12 / 12 \mathrm{~h}$ light dark cycle. Animals had free access to standard pellet diet and water ad libitum. All animal experiments were carried out in accordance with the guidelines of Committee for the Purpose of Control and Supervision on Experiments on Animals. The institute animal ethical committee has given approval for conducting animal experiments (HPI/08/60/ IAEC/0060).

\section{Plant extract preparation}

The whole plant of Passiflora nepalensis Walp., Passifloraceae, were collected in the month of October from the Eastern part of India (Sikkim Himalayas). The Herbarium specimen (No. 168) of plant was deposited in the Department of Pharmacognosy and identified from Himalayan Pharmacy Institute, Majhitar. The whole plant was dried in shade and powdered (no. 60 mesh) and 500 $\mathrm{g}$ of the dried powder was soxhlet extracted successively with petroleum ether, chloroform and methanol. The weight of methanolic extract after drying was calculated as $55.87 \mathrm{~g}$.

\section{Acute toxicity study}

The acute toxicity study of MPN was performed (Turner, 1965; Veerappan et al., 2007). The dead animals obtained from primary screening studies, LD50 value determination experiments and the acute studies were subjected to post mortem studies. The external appearance of the dead animals, the appearance of the viscera, heart, lungs, stomach, intestine, liver, kidney, spleen and brain were carefully noted and any apparent and significant features or differences from the normal were recorded.

\section{Determination of LD50 value by graphical method}

Wister albino rats of both sex and of approximately of the same weight were divided into groups, each containing four animals for the purpose of determining the LD50 value. Each group was caged separately. Each animal in every group was administered with an extract of a pre-determined dose per oral $(1000-2500 \mathrm{mg} / \mathrm{kg})$. About $24 \mathrm{~h}$ later, the number of dead animals were recorded. The data were tabulated. The toxicological effect was assessed on the basis of mortality, which was expressed as on LD50 value. In the groups with no dead animals and in the groups with only dead animals, the obtained percentages were corrected using the formulae:

Correction formula for $0 \%$ dead group $=100(0.25 / \mathrm{n})$,

Correction formula for $100 \%$ dead group $=100(n-$ $0.25 / \mathrm{n})$,

Where ' $n$ ' represents the number of animals in the group. After correction, the percentages were converted into probits and the values were plotted against $\log$ dose. The LD50 value was determined by finding the dose that was intersected by probit 5 (Veerappan et al., 2007).

\section{Sub-acute toxicity studies}

The sub-acute toxicity study of MPN was performed (Turner, 1965; Veerappan et al., 2007). Wister albino rats were divided into four groups of five animals each. Each group was treated with different dose of MPN (40, 80, 160 and $320 \mathrm{mg} / \mathrm{kg}$ ) derived from Passiflora nepalensis, p.o. per day, for fourteen consecutive days. On the fifteenth day, the animals were sacrificed with approximately $100 \mathrm{mg} / \mathrm{kg}$ body wt sodium phenobarbital administered i.p. and organ tissues such as liver, kidney, uterus and heart were surgically removed for histopathological studies. First the organs were carefully examined macroscopically for any abnormal, pathological signs of toxicity. All animals were subjected to gross necropsy, which included an external examination of all body orifices and surfaces and an examination of all cranial, thoracic $\&$ abdominal organs. Gross pathology findings were recorded. For histopathological studies the tissues were fixed with normal saline solution for $48 \mathrm{~h}$, dehydrated with progressively increasing concentrations of alcohol and finally with absolute alcohol, cleaned with xylol and infiltrated with molten paraffin wax at $50{ }^{\circ} \mathrm{C}$. Finally they were prepared as wax blocks with proper tissue-morphological orientations. The wax blocks were sectioned using a microtome suitable for microscopic studies. The suitable sections so obtained were then taken on glass slides. The wax was cleared with xylol and xylol was cleared with absolute alcohol, then progressively dehydrated with gradually increasing dilutions of alcohol and stained with eosin and hematoxylin. They were then once again dehydrated, cleared with xylol, mounted and covered 
with cover slips. The sections were carefully examined under the microscope at low as well as high power. Any histopathological changes deviant from the normal were carefully recorded.

\section{Sample preparation}

On the $15^{\text {th }}$ day, the venous blood was collected from the experimental animals using the method described previously (Narayanan et al., 1984). The collected blood was centrifuged at $3000 \mathrm{rpm}$ for $5 \mathrm{~min}$ (Ogbu \& Okechukwu, 2001) and a Pasteur pipette was used to collect the supernatant (i.e. the serum) which was stored frozen until needed for analysis.

\section{Biochemical assays}

Concentrations of serum sodium and potassium ions were determined by flame photometry using the Jenway Clinical PFP7 flame photometer. Serum urea concentration was estimated by the diacetylmonoxime assay (Veniamin \& Lemonias, 1970). Serum creatinine concentration was determined using Jaffe's reaction (Cook, 1975). Serum albumin concentration was estimated using the albumin-bromocresol green reaction method (Grant \& Kachmar, 1987). Serum phosphate and calcium ions concentration were determined by the method of Goldenberg (Goldenberg \& Fernandez, 1966). Serum total cholesterol and HDL-cholesterol concentrations were determined by the methods of Fredrick (Fredrick et al., 1967). Frozen tissue samples of the rat liver, kidney and heart were weighed and homogenized $(1: 10, \mathrm{w} / \mathrm{v})$ in $100 \mathrm{mmol} / \mathrm{L}$ phosphate buffer ( $\mathrm{pH} 7.4$ ) containing $0.05 \%$ sodium azide in an ice bath. The homogenate was centrifuged at 5000 rpm for $10 \mathrm{~min}$. The supernatant was frozen at -78 ${ }^{\circ} \mathrm{C}$ in aliquots until used for biochemical assays. The protein content of the supernatant was determined by the Bradford method (Bradford, 1976). Thiobarbituric acid reactive substances (TBARS) levels in the tissues were determined by the method described by Ohkawa (Ohkawa et al., 1979). Glutathione peroxidase (GSHPx) [EC 1.11.1.9] was estimated by the method of Ellman (Ellman, 1959). Superoxide dismutase (SOD) [EC 1.15.1.1] levels in the tissues were determined by the method described by Kakkar (Kakkar et al., 1984). Catalase (CAT) [EC 1.11.1.6] level was estimated by the method described by Aebi (Aebi, 1984).

\section{Statistical analysis}

All the data were expressed as mean \pm SEM $(n=5)$. The mean of the different groups were compared using one-way analysis of variance followed by Dunnet multiple comparisons tests.

\section{Results}

Acute toxicity study

The dead animals obtained from the acute toxicity study experiments usually presented with their respiratory arrest and convulsion. Apart from these characteristic observations, no other significant observation deviant from the normal was seen in these dead animals. The LD50 value of MPN was calculated as $1566.82 \mathrm{mg} / \mathrm{kg}$ (Table 1).

Table 1. Acute toxicity study of MPN.

\begin{tabular}{lccccc}
\hline S. No. & $\begin{array}{c}\text { Dose } \\
(\mathrm{mg} / \mathrm{kg})\end{array}$ & Log dose & $\begin{array}{c}\% \\
\text { Mortality }\end{array}$ & $\begin{array}{c}\text { Corrected } \% \\
\text { mortality }\end{array}$ & Probit \\
\hline 1. & 1000 & 3.00 & 0 & 6.25 & 3.45 \\
2. & 1500 & 3.17 & 25 & 25 & 4.33 \\
3. & 2000 & 3.30 & 50 & 50 & 5.00 \\
4. & 2500 & 3.39 & 100 & 93.75 & 6.55 \\
\hline
\end{tabular}

Sub-acute toxicity study

Cage side observations

The MPN did not show any adverse effect during sub-acute toxicity study (Chart 1).

Chart 1. Cage side observations for all animals during subacute toxicity studies.

\begin{tabular}{|clc|}
\hline S. No. & Parameters cage side & Observations \\
\hline 1. & Condition of the fur & Normal \\
2. & Skin & Normal \\
3. & Abdominal distension & Nil \\
4. & Eyes -dullness & Nil \\
5. & Eyes - opacities & Nil \\
6. & Pupil diameter & Normal \\
7. & Color \& consistency of the faces & Normal \\
8. & Wetness or soiling of the perineum & Nil \\
9. & Condition of teeth & Normal \\
10. & Breathing abnormalities & Nil \\
11. & Gait & Normal \\
\hline
\end{tabular}

Serum electrolytes and biomolecules

The extract did not significantly alter $(p>0.05)$ serum concentrations of sodium ion, potassium ion, phosphate ion, urea, creatinine and total cholesterol at all doses administered compared to controls (Tables 2 and $3)$. However, the extract significantly increased $(p<0.05)$ serum concentrations of calcium ion at dose level of 40 and $80 \mathrm{mg} / \mathrm{kg}$, and $(p<0.01)$ at dose level of 160 and 320 $\mathrm{mg} / \mathrm{kg}$ (Table 2). The extract at 160 and $320 \mathrm{mg} / \mathrm{kg}$ b.w. significantly increased $(p<0.05$ and $p<0.01)$ the level of 
serum HDL-cholesterol. However it significantly reduced $(p<0.05)$ the level of albumin at dose of $40 \mathrm{mg} / \mathrm{kg}$, and $(p<0.01)$ at 80,160 and $320 \mathrm{mg} / \mathrm{kg}$ respectively (Table 3$)$.

\section{Other biochemical parameters}

Thiobarbituric acid reactive substances

The extract did not significantly alter $(p>0.05)$ TBARS level in tissue homogenate of liver, kidney and heart (Tables 4, 5 and 6).
Superoxide dismutase

MPN did not significantly alter $(p>0.05)$ the level of SOD at 40 and $80 \mathrm{mg} / \mathrm{kg}$ in liver but it significantly increased $(p<0.05$ and $p<0.01)$ their levels at doses of 160 and $320 \mathrm{mg} / \mathrm{kg}$ respectively. Similarly in case of kidney and heart, the extract did not significantly alter the level of SOD at 40 and $80 \mathrm{mg} / \mathrm{kg}$ but it significantly $(p<0.01)$ increased their level at higher doses i.e. 160 and $320 \mathrm{mg}$ / $\mathrm{kg}$ (Tables 4, 5 and 6).

Table 2. Effect of MPN on serum electrolytes on $15^{\text {th }}$ day.

\begin{tabular}{ccccc}
\hline \multirow{2}{*}{ Group } & \multicolumn{4}{c}{ Concentration $(\mathrm{mmol} / \mathrm{L})$} \\
\cline { 2 - 4 } & $\mathrm{Na}^{+}$ & $\mathrm{K}^{+}$ & $\mathrm{Ca}^{2+}$ & $\mathrm{PO}_{4}$ \\
\hline Control & $141.2 \pm 0.80$ & $4.34 \pm 0.14$ & $1.54 \pm 0.15$ & $1.05 \pm 0.06$ \\
$40 \mathrm{mg} / \mathrm{kg}$ & $140.4 \pm 1.03$ & $4.38 \pm 0.26$ & $2.12 \pm 0.08^{\mathrm{b}}$ & $0.95 \pm 0.01$ \\
$80 \mathrm{mg} / \mathrm{kg}$ & $142.2 \pm 0.58$ & $4.36 \pm 0.15$ & $2.18 \pm 0.14^{\mathrm{b}}$ & $1.09 \pm 0.06$ \\
$160 \mathrm{mg} / \mathrm{kg}$ & $143.2 \pm 0.48$ & $4.42 \pm 0.20$ & $2.22 \pm 0.09^{\mathrm{c}}$ & $0.91 \pm 0.02$ \\
$320 \mathrm{mg} / \mathrm{kg}$ & $142.8 \pm 1.49$ & $4.48 \pm 0.17$ & $2.27 \pm 0.18^{\mathrm{c}}$ & $1.07 \pm 0.06$ \\
\hline
\end{tabular}

Values are mean $\pm \operatorname{SEM}(\mathrm{n}=5)$. Values in the same column with different alphabet superscripts are significantly different at ${ }^{\mathrm{b}} p<0.05$, ${ }^{\mathrm{c}} p<0.01$. Values are obtained by one way ANOVA followed by Dunnett multiple comparisons test.

Table 3. Effect of MPN on serum biomolecules on $15^{\text {th }}$ day.

\begin{tabular}{cccccc}
\hline Group & Urea conc $(\mathrm{mmol} / \mathrm{L})$ & Creatinine conc $(\mu \mathrm{mol} / \mathrm{L})$ & Albumin conc $(\mathrm{g} / \mathrm{L})$ & HDL-Ch $(\mathrm{mmol} / \mathrm{L})$ & Total-Ch $(\mathrm{mmol} / \mathrm{L})$ \\
\hline Control & $8.24 \pm 0.30$ & $68.41 \pm 0.30$ & $32.30 \pm 0.57$ & $0.79 \pm 0.03$ & $2.53 \pm 0.15$ \\
$40 \mathrm{mg} / \mathrm{kg}$ & $7.98 \pm 0.29$ & $69.99 \pm 0.59$ & $30.46 \pm 0.66^{\mathrm{b}}$ & $0.86 \pm 0.02$ & $2.27 \pm 0.26$ \\
$80 \mathrm{mg} / \mathrm{kg}$ & $7.96 \pm 0.31$ & $71.91 \pm 1.98$ & $27.41 \pm 0.35^{\mathrm{c}}$ & $1.01 \pm 0.05$ & $2.45 \pm 0.12$ \\
$160 \mathrm{mg} / \mathrm{kg}$ & $8.02 \pm 0.31$ & $70.81 \pm 1.08$ & $26.61 \pm 0.35^{\mathrm{c}}$ & $1.15 \pm 0.09^{\mathrm{b}}$ & $2.42 \pm 0.09$ \\
$320 \mathrm{mg} / \mathrm{kg}$ & $8.48 \pm 0.34$ & $69.15 \pm 0.78$ & $27.15 \pm 0.21^{\mathrm{c}}$ & $1.23 \pm 0.16^{\mathrm{c}}$ & $2.58 \pm 0.16$ \\
\hline
\end{tabular}

Values are mean $\pm \operatorname{SEM}(\mathrm{n}=5)$. Values in the same column with different alphabet superscripts are significantly different at ${ }^{\mathrm{b}} p<0.05,{ }^{\mathrm{c}} p<0.01$. Values are obtained by one way ANOVA followed by Dunnett multiple comparisons test.

Table 4. Effect of MPN on liver on $15^{\text {th }}$ day.

\begin{tabular}{ccccc}
\hline Group & TBARS (nmol/mg-protein) & SOD (IU/mg-protein) & CAT (IU/mg-protein) & GSH-Px (U/mg-protein) \\
\hline Control & $1.75 \pm 0.41$ & $1.49 \pm 0.16$ & $0.23 \pm 0.37$ & $2.47 \pm 0.11$ \\
$40 \mathrm{mg} / \mathrm{kg}$ & $1.67 \pm 0.39$ & $1.60 \pm 0.11$ & $0.26 \pm 0.01$ & $2.68 \pm 0.27$ \\
$80 \mathrm{mg} / \mathrm{kg}$ & $1.51 \pm 0.32$ & $1.64 \pm 0.10$ & $0.29 \pm 0.18^{\mathrm{b}}$ & $2.57 \pm 0.29$ \\
$160 \mathrm{mg} / \mathrm{kg}$ & $1.52 \pm 0.39$ & $2.12 \pm 0.14^{\mathrm{b}}$ & $0.31 \pm 0.14^{\mathrm{c}}$ & $3.66 \pm 0.37^{\mathrm{b}}$ \\
$320 \mathrm{mg} / \mathrm{kg}$ & $1.78 \pm 0.20$ & $2.36 \pm 0.15^{\mathrm{c}}$ & $0.30 \pm 0.20^{\mathrm{c}}$ & $3.81 \pm 0.38^{\mathrm{b}}$
\end{tabular}

Values are mean $\pm \operatorname{SEM}(\mathrm{n}=5)$. Values in the same column with different alphabet superscripts are significantly different at ${ }^{\mathrm{b}} p<0.05$, ${ }^{\mathrm{c}} p<0.01$. Values are obtained by one way ANOVA followed by Dunnett multiple comparisons test.

Table 5. Effect of MPN on kidney on $15^{\text {th }}$ day.

\begin{tabular}{ccccc}
\hline Group & TBARS (nmol/mg-protein) & SOD (IU/mg-protein) & CAT (IU/mg-protein) & GSH-Px (U/mg-protein) \\
\hline Control & $21.36 \pm 0.53$ & $6.97 \pm 0.24$ & $0.22 \pm 0.67$ & $2.12 \pm 0.06$ \\
$40 \mathrm{mg} / \mathrm{kg}$ & $22.89 \pm 0.75$ & $7.25 \pm 0.20$ & $0.23 \pm 0.67$ & $2.23 \pm 0.06$ \\
$80 \mathrm{mg} / \mathrm{kg}$ & $22.76 \pm 0.40$ & $7.26 \pm 0.20$ & $0.25 \pm 0.96^{\mathrm{b}}$ & $2.56 \pm 0.05^{\mathrm{b}}$ \\
$160 \mathrm{mg} / \mathrm{kg}$ & $22.05 \pm 0.64$ & $8.64 \pm 0.25^{\mathrm{c}}$ & $0.30 \pm 0.74^{\mathrm{c}}$ & $2.84 \pm 0.13^{\mathrm{c}}$ \\
$320 \mathrm{mg} / \mathrm{kg}$ & $21.17 \pm 0.87$ & $9.13 \pm 0.54^{\mathrm{c}}$ & $0.31 \pm 0.30^{\mathrm{c}}$ & $2.88 \pm 0.17^{\mathrm{c}}$ \\
\hline
\end{tabular}

Values are mean \pm SEM $(\mathrm{n}=5)$. Values in the same column with different alphabet superscripts are significantly different at ${ }^{\mathrm{b}} p<0.05,{ }^{\mathrm{c}} p<0.01$. Values are obtained by one way ANOVA followed by Dunnett multiple comparisons test. 
Table 6. Effect of MPN on heart on $15^{\text {th }}$ day.

\begin{tabular}{ccccc}
\hline Group & TBARS (nmol/mg-protein) & SOD (IU/mg-protein) & CAT (IU/mg-protein) & GSH-Px (U/mg-protein) \\
\hline Control & $22.38 \pm 0.73$ & $2.48 \pm 0.27$ & $0.21 \pm 0.50$ & $2.34 \pm 0.10$ \\
$40 \mathrm{mg} / \mathrm{kg}$ & $23.72 \pm 1.47$ & $2.68 \pm 0.25$ & $0.23 \pm 0.24$ & $2.32 \pm 0.07$ \\
$80 \mathrm{mg} / \mathrm{kg}$ & $22.36 \pm 0.83$ & $3.07 \pm 0.28$ & $0.23 \pm 0.86$ & $2.50 \pm 0.11$ \\
$160 \mathrm{mg} / \mathrm{kg}$ & $24.76 \pm 1.33$ & $3.69 \pm 0.20^{\mathrm{c}}$ & $0.29 \pm 0.25^{\mathrm{c}}$ & $3.39 \pm 0.07^{\mathrm{c}}$ \\
$320 \mathrm{mg} / \mathrm{kg}$ & $22.67 \pm 0.79$ & $4.24 \pm 0.19^{\mathrm{c}}$ & $0.32 \pm 0.24^{\mathrm{c}}$ & $3.87 \pm 0.13^{\mathrm{c}}$ \\
\hline
\end{tabular}

Values are mean \pm SEM $(\mathrm{n}=5)$. Values in the same column with different alphabet superscripts are significantly different at ${ }^{\mathrm{b}} p<0.05$, ${ }^{\mathrm{c}} p<0.01$. Values are obtained by one way ANOVA followed by Dunnett multiple comparisons test.

\section{Catalase}

The hepatic and renal catalase were not significantly $(p>0.05)$ altered in rats treated with $40 \mathrm{mg} / \mathrm{kg}$ of MPN but it significantly $(p<0.05)$ increased the level of CAT at $80 \mathrm{mg} / \mathrm{kg}$ b.w. The extract at dose levels of 160 and $320 \mathrm{mg} / \mathrm{kg}$ significantly $(p<0.01)$ increased CAT activity in both the liver and kidney. There were no significant $(p>0.05)$ alterations observed at 40 and $80 \mathrm{mg} / \mathrm{kg}$ of MPN in myocardium, however MPN significantly $(p<0.01)$ increased their levels at higher doses i.e. 160 and $320 \mathrm{mg} /$ $\mathrm{kg}$ (Tables 4, 5 and 6).

\section{Glutathione peroxidase}

The hepatic GSH-Px was not significantly $(p>0.05)$ altered in rats treated with 40 and $80 \mathrm{mg} / \mathrm{kg}$ of MPN, but MPN significantly $(p<0.05)$ increased the level of GSH-Px at 160 and $320 \mathrm{mg} / \mathrm{kg}$ b.w. The GSH-Px level in kidney was not significant at $40 \mathrm{mg} / \mathrm{kg}$ of MPN but it significantly increased $(p<0.05)$ their level at $80 \mathrm{mg} / \mathrm{kg}$. The MPN significantly increase $(p<0.05$ and $p<0.01)$ their level at 160 and $320 \mathrm{mg} / \mathrm{kg}$ respectively in kidney. The myocardium GSH-Px level was not significantly altered at 40 and $80 \mathrm{mg} / \mathrm{kg}$ of MPN but significantly $(p<0.01)$ increased at dose levels of 160 and $320 \mathrm{mg} / \mathrm{kg}$ (Tables 4, 5 and 6).

\section{Histopathology}

Gross necropsy findings did not show any adverse effects in any organs during sub-acute toxicity study. No statistically significant differences in organ weights were present in any of the male and female rats receiving the MPN as compared to the normal control group. Moreover, no lethality was recorded for any dose upto the maximum of $320 \mathrm{mg} / \mathrm{kg}$ of MPN during the fourteen days of treatment. No histopathological changes were noted in the high dose groups as compared to control, data not shown.

\section{Discussion}

In the toxicity studies, including the acute, sub-acute toxicities and LD50 value were elucidated in experimental rats. Herbal medicines are used by up to $80 \%$ of the population in developing countries (Veerappan et al., 2007). Despite widespread use, few scientific studies have been undertaken to ascertain the safety and efficacy of traditional remedies. The present investigation shows that the MPN is nontoxic via oral route in rats, at least up to maximum dose of $1000 \mathrm{mg} / \mathrm{kg}$ b.w. acutely and $320 \mathrm{mg}$ / kg b.w. sub-acutely.

Increased serum calcium ion concentration in the extract treated rats suggests increased intestinal absorption of calcium (Katzung, 2006). This may result from increased conversion of vitamin $\mathrm{D}$ to the active form, 1,25-dihydroxyvitamin $\mathrm{D}_{3}$, which has been reported to be the primary hormone that mediates calcium absorption in the intestine. Vitamin D is first hydroxylated in the liver to 25-hydroxyvitamin $\mathrm{D}_{3}$ which is further hydroxylated in the kidney to 1,25-dihydroxyvitamin $\mathrm{D}_{3}$ by hydroxylases (Baker, 2002). 1,25-dihydroxy vitamin $\mathrm{D}_{3}$ has been reported to stimulate the production of the transporter protein necessary for calcium transport across the epithelium of the small intestine (Baker, 2002). Thus, the extract may possess the potential of causing an imbalance in homeostatic regulation of calcium ion in subjects. However, hypocalcemia is a common feature of malaria (Prabha et al., 1998; John et al., 1995). Ability of the extract to increase serum calcium level suggests one of the possible mechanisms by which it alleviates complications of malaria, being a disease for which it is also used in folkmedicine. Reduction in serum albumin concentration by the extract suggests impairment in the role of the liver to synthesize the protein (Grant \& Kachmar, 1987). Decrease in serum albumin level has adverse consequences. Albumin in conjunction with other plasma proteins (being large colloidal molecules) cannot diffuse through the thin capillary wall membranes as most other plasma solutes. Thus they are entrapped in the vascular system and exert a colloidal osmotic pressure which serves to maintain a normal blood volume and normal water content in the interstitial fluid and the tissues (Grant \& Kachmar, 1987). Albumin fraction is the most important in maintaining this normal colloidal osmotic pressure in blood. Thus decrease in serum albumin concentration, if not checked, implies 
that water will diffuse from the blood vessels and enter interstitial fluid and the tissues, leading to accumulation of water in such tissues (Grant \& Kachmar, 1987). Increased serum HDL-cholesterol concentration without alteration in the total cholesterol concentration suggests its likelyhood of protecting against diseases such as atherosclerosis, $320 \mathrm{mg} / \mathrm{kg}$ of MPN was found to be most active in this regard. Since the plant is used to treat diabetes mellitus in folkmedicine, this may be one of the possible mechanisms by which it alleviates complications of diabetes e.g. cardiovascular disease.

MPN increased the GSH-Px activity in liver. GSH-Px is an enzyme which prevents the generation of hydrogen peroxide and alkyl hydroperoxides in association with GSH and GSH-reductase, as well as the generation of more harmful metabolites such as the hydroxyl radical (Therond et al., 2000; Parodi, 2007). It also elevated the level of other endogenous antioxidant enzymes such as SOD and CAT in liver, in all the cases 160 and 320 $\mathrm{mg} / \mathrm{kg}$ of MPN were most active. The 'primary' reactive oxygen species $\mathrm{O}^{2-}$ is depleted by a dismutation reaction catalyzed by SOD and the less reactive $\mathrm{H}_{2} \mathrm{O}_{2}$ is produced. However, $\mathrm{O}^{2-}$ can further interact with other molecules to generate 'secondary' reactive species, either by directly or prevalently through enzyme- or metal-catalyzed processes (Valko et al., 2006). $\mathrm{H}_{2} \mathrm{O}_{2}$ is further converted to $\mathrm{H}_{2} \mathrm{O}$ and $\mathrm{O}_{2}$ by the enzymes CAT and GSH-Px and this reaction prevents the formation of the highly reactive $\mathrm{OH}-$. In addition, GSH-Px simultaneously consumes reduced glutathione to give oxidized tripeptide glutathione in this reaction (Valko et al., 2006). In our study the levels of SOD, GSH-Px and CAT increased significantly in kidney and the dose level of 160 and $320 \mathrm{mg} / \mathrm{kg}$ of MPN were found most effective. This finding may reduce the renal oxidative stress or renal ischemia by its antioxidant effect. Significantly GSH-Px competes with CAT for $\mathrm{H}_{2} \mathrm{O}_{2}$ as a substrate and is the major source of protection against low levels of oxidative stress (Valko et al., 2006). Therefore, an alternative explanation would be that even the magnitude of oxidative stress is low after the effective scavenging of $\mathrm{O}^{2-}$ by SOD, most of the residual $\mathrm{H}_{2} \mathrm{O}_{2}$ might have been eliminated by CAT rather than by GSH-Px as a result of this competition. Oral administration of MPN caused significant rise in myocardial endogenous antioxidants (SOD, GSH-Px and CAT) and extract at dose levels of 160 and $320 \mathrm{mg} / \mathrm{kg}$ were most active. Recent studies show that various plants and plant extracts can also stimulate the synthesis of cellular antioxidants (Pathania et al., 1998; Gauthaman et al., 2001; Banerjee et al., 2002). Augmentation of endogenous antioxidants by therapeutic substances has recently evoked scientific interest because any such property of a therapeutic agent can be expected to cause significant improvement in the endogenous defense against oxidative stress (Tosaki et al., 1994), so MPN may be helpful for treatment of ischemic heart disease as used by folklore medicine. In conclusion, findings of the present study indicated that MPN have antioxidant effect on liver, kidney and heart, by induction of endogenous antioxidant enzymes without any significant adverse effect. Oral administration of the extract of Passiflora nepalensis at doses of $40,80,160$ and $320 \mathrm{mg} / \mathrm{kg}$ body wt for fourteen consecutive days to male and female Wister rats did not induce significant short-term toxicity. Collectively these data demonstrate that the methanolic extract of Passiflora nepalensis have a high margin of safety. Further studies are required to evaluate the effect of Passiflora nepalensis against cardiac, hepatic, renal and cerebral ischemia.

\section{Acknowledgement}

The author(s) are thankful to All India Council for Technical Education, New Delhi for their financial support to carry-out this research work (AICTE/F. No: 8023/BOR/ RID/RPS-206/2007).

\section{References}

Aebi H 1984. Catalase in vitro. In Packer L, Orlando FL (eds.). Methods in Enzymology. New York: Academic Press, p. 121-26.

Baker HM 2002. Nutrition and dietetics for health care. Edinburgh: Churchill Livingstone.

Banerjee SK, Dinda AK, Manchanda SC, Maulik SK 2002. Chronic garlic administration protects rat heart against oxidative stress induced by ischemic reperfusion injury. BMC Pharmacology 2: 16.

Bradford MM 1976. A rapid and sensitive method for the quantitation of microgram quantities of protein utilizing the principle of protein-dye binding. Anal Biochem 7: 248-54.

Cook GH 1975. Factors influencing the assay of creatinine. Ann Clin Bioch 12: 219-32.

Dhawan K, Dhawan S, Sharma A 2004. Passiflora: a review update. J Ethnopharmacol 94: 1-23.

Ellman GL 1959. Tissue sulphydryl groups. Arch Biochem Biophys 82: 70-77.

Fredrick DS, Levy RI, Lees RS 1967. Fat transport in lipoproteins - an integrated approach to mechanisms and disorders. $N$ Engl J Med 276: 148-56.

Gauthaman K, Maulik M, Kumari R, Manchanda SC, Dinda AK, Maulik SK 2001. Effect of chronic treatment with bark of Terminalia arjuna, a study on the isolated ischemic reperfused rat heart. J Ethnopharmacol 75: 197-201.

Goldenberg H, Fernandez A 1966. Simplified method for the estimation of inorganic phosphorus in body fluids. Clin Chem 12: 871-82.

Grant GH, Kachmar JF 1987. In Tietz NW (ed.). Fundamental of clinical Chemistry. Philadelphia: WB Saunders Company, p. 298-320.

John AS, Davis TM, Binh TQ, Thu LT, Dyer JR, Anh TK 1995. Mineral homoeostasis in acute renal failure complicating severe falciparum malaria. J Clin Endocrinol Metab 80: 2761-67.

Kakkar P, Das B, Viswanatham PN 1984. A modified 
spectrophotometric assay of superoxide dismutase. Indian J Biochem Biophys 21: 130-32.

Katzung BG 2006. Basic and clinical pharmacology. New York: McGraw-Hill Medical Publishing Division.

Kinghorn GR 2001. Passion, stigma and STI. Sex Transm Inf 77: 370-75.

Narayanan CR, Joshi DD, Mujumdar AM 1984. Hypoglycemic action of Bougainvillea spectabilis leaves. Curr Sci 53: 579-81.

OECD Test Guidelines 1980. OECD expert group on good laboratory practices, Paris.

Ogbu SI, Okechukwu EI 2001. The effect of storage temperature prior to separation on plasma and serum potassium. $J$ Medical Lab Sci 10: 1-4.

Okhawa H, Qohishi N, Yagi K 1979. Assay of lipid peroxides in animal tissues by Thiobarbituric acid reaction. Anal Biochem 95: 351-58.

Parodi PW 2007. A role for milk proteins and their peptides in cancer prevention. Curr Pharm Des 13: 813-828.

Patel SS 2009. Morphology and pharmacology of Passiflora edulis: a review. J Herb Med Toxicol 3: 175-81.

Patel SS, Verma NK, Gauthaman K 2009. Passiflora incarnata Linn: a review on morphology, phytochemistry and pharmacological aspects. Phcog Rev 3: 175-81.

Patel SS, Verma NK, Ravi V, Gauthaman K, Soni N 2010. Antihypertensive effect of an aqueous extract of Passiflora nepalensis Walp. IJARNP 3: 23-28.

Pathania V, Syal N, Hundal MH, Khanduja KL 1998. Geriforte stimulates antioxidant defense system. Indian J Exp Biol 36: 414-17.

Prabha MR, Pereira P, Chowta N, Hegde BM 1998. Clinical implications of hypocalcemia in malaria. Indian $\mathrm{J}$ Med Res 108: 62-65.

The Wealth of India 2001. A dictionary of Indian raw materials and industrial products. CSIR 7: 278-79.

Therond P, Bonnefont RD, Davit SA, Conti M, Legrand A 2000. Biomarkers of oxidative stress: an analytical approach. Curr Opin Clin Nutr Metab Care 3: 373-84.

Tosaki A, Engelman DT, Pali T, Engelman RM, Droy LMT 1994. Ginkgo biloba extract (egb-761) improves postischemic function in isolated preconditioned working rat hearts. Coronary Artery Dis 5: 443-50.

Turner RA 1965. Screening Methods in Pharmacology. New York: Academic press.

Valko M, Rhodes CJ, Moncol J 2006. Free radicals, metals, and antioxidants in oxidative stress-induced cancer. Chem Biol Interact 160: 1-40.

Veerappan A, Miyasaki S, Kadarkaraisamy M, Ranganathan D 2007. Acute and subacute toxicity studies of Aegle marmelos Corr., an Indian medicinal plants. Phytomedicine 14: 209-15.

Veniamin MP, Lemonias CV 1970. Chemical basis of the carbamidodiacetyl micro-method for estimation of urea, citrulline and carbamyl derivatives. Clin Chem 16: 3-6.

\section{*Correspondence}

Sita Sharan Patel

Department of Pharmacology, Himalayan Pharmacy Institute Majhitar, East Sikkim-737136, India

Tel.: +91 7869106259

Fax: +913592246462 